\title{
GLOBALIZAÇÃo, DIVERSIDAdE CULTURAL E LUSOFONIAS: CIRCULAÇÃO TRANS-ESPACIAL DA FALA PORTUGUESA E SUA RELAÇÃO COM OUTRAS FALAS
}

\author{
Armando Jorge Lopes
}

\begin{abstract}
Resumo
Discuto transdisciplinarmente questões várias que envolvem os conceitos de globalização, diversidade cultural e lusofonia, recorrendo a travessias e a passagens mediadas pela Linguística Aplicada e suportadas pela Planificação Linguística e pela Política Linguística. A travessia, envolta em novidade e perigosidade, fala-nos de oceanos, proporcionando-nos desafios complexos, e colocando-nos, por vezes, em sobressalto. A passagem parece ser mais controlada, associada a experiências com menos enigmas e mais seguras, talvez porque habitualmente se avistam as margens de um lado e do outro, a partir de diferentes pontos do rio, quando efectuamos a passagem. No rio passa-se de uma margem para a outra. E no oceano, o que acontece? Numa perspectiva transdisciplinar e através da linguística aplicada, a lusofonia e a sua contextualização, incluindo a diversidade cultural num mundo pretendido global é, por mim entendida, como sendo a travessia. Através da Planificação Linguística e da Política Linguística, que se constituem em instrumento útil para um esboço possível de uma noção virada para o futuro, a lusofonia é aqui entendida como uma passagem. $\mathrm{O}$ enfoque do presente artigo recai, pois, sobre o conceito de lusofonia como lugar de reflexão, de conhecimento e de reconhecimento de si e do Outro, conceito este instanciado pela noção da relação vis-a-vis globalização e pela essência aqui representada pelo sistema ecológico linguístico do Português.
\end{abstract}

\section{GLOBALISATION, CULTURAL DIVERSITY AND LUSOPHONY: TRANS-SPATIAL CIRCUlation OF PORTUguese SPEECH AND ITS RELATIONSHIP WITH OTHER SPEECHES}

\begin{abstract}
I shall discuss several questions involving the concepts of globalisation, cultural diversity and Lusophony in a transdisciplinary fashion, resorting to the notions of crossings and passages, mediated by Applied Linguistics and supported by Language Planning and Language Policy. The crossing, wrapped in novelty and perilousness, speaks of oceans, affording us complex challenges and, at times, frightening us. The passage seems to be more controlled, and associated with less enigmatic and more secure experiences, perhaps because both banks of a river can usually be seen from any point as we pass through it. In a river, we travel across from one bank to the other. And in the ocean, what happens? Lusophony and its contextualisation, in my opinion, is the crossing, viewed from a transdisciplinary perspective and through applied linguistics, including cultural diversity in a world claimed as global. Through Language Planning and Language Policy, both established as useful tools for a possible outline of some futuristic notion, Lusophony is here understood as passage. The focus of the present article falls therefore upon the concept of Lusophony as a place of reflection, of knowledge as well as recognition of oneself and the Other.
\end{abstract}


This concept of Lusophony is instantiated by the notion of relation vis-à-vis globalisation and by the essence here portrayed by the linguistic ecological system of Portuguese.

KEYWORDS

Lusophony; globalisation; relation; Language Planning and Policy; Applied Linguistics

\section{A MINHA POSTURA INVESTIGATIVA SOBRE A GLOBALIZAÇÃO, DIVERSIDADE CULTURAL E LUSOFONIA ${ }^{1}$}

A abordagem da realidade não pode fundir opostos metodológicos, por exemplo, entre outros, a experimentação que se pauta por procedimentos rígidos e as histórias que se reconstroem subjectivamente. Por isso, reforço a ideia da actuação a nível multipartido, uma actuação através da qual podemos, por exemplo, explicar um fenómeno ou evento como entidade física, e uma outra, pela qual procuramos compreender o evento como motivos simbólicos. Mas tal abordagem pluralista requer dos pesquisadores ajustamentos mentais, porque, sendo a pesquisa experimental e a pesquisa etnográfica tão diferentes, é difícil pensar ou trabalhar de uma só vez nas várias direcções. O que é possível, através de cuidadosas mudanças de velocidade, é alternar entre as diferentes abordagens, desenvolvendo uma tensão criativa entre pontos de vista alternativos. Tanto para realizar experiências, como para fazer histórias, os pesquisadores precisam de orientações sobre que tópicos devem ser explicados e que tópicos devem ser interpretados. $\mathrm{Na}$ linguística, há, por exemplo, uma certa concordância em separar o processo de aquisição de língua do processo de utilização de língua, e esta divisão serve apenas para sublinhar os nossos pontos de vista, isto é, ol harmos para a língua como objecto ou olharmos para a língua como um complexo de motivos simbólicos. As ciências humanas e as ciências sociais, quando comparadas com as ciências naturais, técnicas e exactas, foram e são ainda na tradição nomotética consideradas primas afastadas. Esta ténue relação tem a ver com o estatuto das próprias ciências sociais em que apenas a psicologia experimental é, por essa tradição, considerada como a ciência social mais nomotética. A visão de Platão, tão enraizada nas ciências naturais e exactas, permanece a ponto da teoria puramente formal constituir a preocupação central dos linguistas generativos transformacionalistas. Há, contudo, desenvolvimentos recentes nas ciências sociais em busca de um paradigma que acolha melhor a dimensão hermenêutica e estabeleça um equilíbrio mais satisfatório entre a dimensão hermenêutica e a dimensão nomotética, como o que está a ser tentado na linguística aplicada, etnometodologia, etnografia educacional, humanismo psicológico e sociologia, refinando e aperfeiçoando as nossas sensibilidades para não corrermos o risco de efectuar interpretações sem sentido.

A postura tradicional na pesquisa e no processo de ensino-aprendizagem é disciplinar porque, na abordagem e análise de uma questão, privilegia o enfoque que se

\footnotetext{
'Investigação desenvolvida no contexto do projeto "Memories, cultures and identities: how the past weights on the present-day intercultural relations in Mozambique and Portugal?", financiado pela Rede Aga Khan para o Desenvolvimento e pela Fundação para a Ciência e Tecnologia.
} 
circunscreve aos parâmetros e limites de uma disciplina ou campo para a entender: por exemplo, tenta-se compreender uma infelicidade discursiva com recurso apenas à disciplina de Análise do Texto. Posteriormente, a chamada postura interdisciplinar passou a associar e a fazer confluir na abordagem e análise de conhecimentos e habilidades de outras disciplinas para além da Análise do Texto como, por exemplo, as disciplinas da Análise do Discurso, Psicologia Behaviorista e Psicologia Cognitiva para procurar entender a questão da infelicidade discursiva na comunicação de falantes e escreventes.

Quanto à postura transdisciplinar na pesquisa e no processo de ensino-aprendizagem, ela opera com base na crença de que há conhecimento, conceitos, habilidades, atitudes e acções que transcendem as fronteiras de uma área disciplinar e que forjam o currículo num todo transdisciplinar coerente que é envolvente, relevante e significativo. Adoptar uma postura transdisciplinar significa que pessoas de duas ou mais disciplinas ensinam, aprendem e trabalham conjuntamente através de fronteiras disciplinares ou profissionais tradicionais. É claro que uma postura transdisciplinar se socorre de posturas interdisciplinares que combinam ou envolvem duas ou mais disciplinas ou campos de estudo e, se socorre ainda por vezes, de posturas intradisciplinares em que o enfoque reside no seio de uma mesma disciplina ou de pessoas que estão activas trabalhando nessa disciplina.

Por outro lado, a multidisciplinaridade, que envolve múltiplas disciplinas académicas visando resolver problemas exteriores às fronteiras habituais, revela reflexões disciplinares paralelas, colocadas lado a lado para consideração, diferentemente da transdisciplinaridade, que é mais integradora e, socialmente, mais inclusiva. A transculturalidade, postura que busca interesses partilhados e valores comuns, assenta na ruptura de fronteiras, sendo acentuadamente diferente da multiculturalidade (ou multiculturalismo) porque nesta postura tende-se a reforçar fronteiras que têm por base heranças culturais do passado: a postura multicultural faz relacionar uma cultura com outra ou outras diferentes, enquanto que a postura transcultural se amplia através de duas ou mais culturas. Na postura multicultural, em que as pessoas vivem, lado a lado, umas com as outras, um determinado grupo cultural não se envolve necessariamente e nem sempre em interacções com outros grupos culturais. Na postura transdisciplinar, o conhecimento gerado em contexto de aplicação não se reduz nunca a nenhuma das disciplinas que concorreram para a sua acumulação, e não se distingue entre conhecimento básico ou puro e conhecimento aplicado, nem entre investigação teórica ou básica e investigação aplicada porque a relação entre estes tipos de conhecimento e idealizações investigativas não ocorre somente num único sentido. Como defendo (Lopes, 1998, p. ix) a propósito da habitual distinção entre a investigação teórica e investigação aplicada, e incluindo mesmo a investigação prática (esta terceira categoria, relacionada com a didáctica, é muitas vezes ignorada ou secundarizada), a saber:

da construção de modelos para explicar um determinado fenómeno à investigação sobre as aplicações a um dado contexto de quadros teóricos numa disciplina $\mathrm{x}$, à utilização prática de dados teóricos e aplicados em métodos de ensino e na aprendizagem na sala de aulas, cada categoria de 
investigação deve idealmente contribuir para a revisão do conteúdo e estrutura das outras categorias.

Dito talvez de forma mais simples: a investigação teórica informa a aplicada e esta, por sua vez, a teórica ou no caso, por exemplo, de preparação e elaboração didáctica de manuais, a investigação aplicada (ou até mesmo a investigação teórica, de forma directa) informa a investigação prática e esta, por sua vez, informa a investigação teórica ou a investigação aplicada. É que a investigação aplicada também tem naturalmente o seu edifício teórico, sendo a postura transdisciplinar de enfoque simultaneamente teórico e aplicado e dirigido para especificadas necessidades sócio-económicas e culturais, através da adopção de múltiplas metodologias de investigação visando criar soluções que respondam a anseios da sociedade, e transformar práticas sociais que requerem alteração ou inovação.

A transdisciplinaridade, termo criado por Jean Piaget em 1970, visa estimular novas compreensões da realidade através da articulação de elementos que atravessam disciplinas, passando entre si e de elementos que vão para além das disciplinas, promovendo a máxima interacção possível entre elas, respeitando todavia as suas individualidades, em que cada uma delas colabora para um saber comum e sem se transformarem numa única disciplina. No caso vertente dos estudos da cultura e da linguagem, a transdisciplinaridade visa igualmente desnaturalizar questões de hegemonia cultural e linguística, sendo o radical trans do termo portador de um sentido de movimento multidireccional e recíproco (nunca de sentido único), de ajuda mútua através da experiência e da justa troca como, em minha opinião, sugerem os termos transculturalidade e translinguísmo.

Para reforçar conceptualmente o aspecto da reciprocidade no âmbito da transdisciplinaridade, translinguísmo e transculturalidade, recorri a investigações no seio da psicologia behaviorista e, em especial, aos paradigmas de transferência de Osgood (1949), nas dimensões da proacção e retroacção. A proacção é uma acção que se antecipa a uma futura situação, não ocorrendo apenas como reacção. Descreve o controlo e o poder que se pode ter para fazer acontecer várias coisas e não apenas para ajustar coisas a uma dada situação, ou esperar que algo aconteça. A retroacção é uma acção recíproca, que descreve um evento, estímulo ou processo que tem efeito sobre efeitos de eventos, estímulos ou processos que ocorreram anteriormente.

Através da proacção são visíveis os efeitos numa determinada tarefa 2, e na sequência da execução de uma tarefa 1; por outro lado, através da retroaç̧ão são visíveis os efeitos da tarefa 2 na tarefa 1 , como aconteceu no passado e continua a acontecer, por exemplo, em relação às transferências linguísticas e culturais da língua portuguesa para as línguas bantu, enriquecendo e complementando reciprocamente as transferências linguísticas e culturais das línguas bantu de Moçambique que, em considerável medida, têm alimentado ao longo das décadas o Português Moçambicano.

A postura transdisciplinar em relação à disciplina da Linguística Aplicada (LA), incide, em minha opinião, na convergência entre a teoria científica e a teoria indigenizada, que é a prática, como lhe chamou James (1993, pp. 17-32). Assim, por exemplo, a postura 
transdisciplinar incide relevantemente em múltiplos espaços e abordagens entre a teoria linguística e a teoria de ensino de línguas, esta que é uma área pioneira da LA (relacionada com as metodologias do processo de ensino-aprendizagem), alimentando-se ambas as teorias, de forma recíproca, como a proacção e retroacção - ou como a unidade na diversidade: Moçambique na CPLP e a CPLP em Moçambique.

É claro que em tal dinâmica, a disciplina da LA, nas suas dimensões teórica e indigenizada, precisaria de se renovar e também através dela a própria linguística geral, que lhe é fundamental, precisaria de se renovar. A este respeito é apropriado o que diz Rajagopalan (2003, pp. 79-80):

o que a lingüística aplicada precisa com urgência é repensar sua própria razão de ser enquanto disciplina e buscar suas próprias credenciais acadêmicas, admitindo até mesmo, como uma das possibilidades no fim dessa trilha, a de a nova disciplina poder vir a ser uma alternativa à disciplina-mãe (i.e. linguistica geral).

E, de seguida, arremata assim: "dito de outra forma, à lingüística aplicada pode estar reservada a tarefa de reanimar a própria disciplina-mãe...que se encontra em estado doentio, necessitando de novo ânimo" (Rajagopalan, 2003, pp. 79-80).

Quanto à transculturalidade, e segundo Mary Louise Pratt, (2005), com quem estou essencialmente de acordo, ela assenta, no conceito que o cubano Fernando Ortiz criou em 1940, à luz do seu pensamento sócio-antropológico (1940/1963): “embora os povos subordinados geralmente não controlem aquilo que emana da cultura dominante, eles determinam, até certo ponto, aquilo que é absorvido pela sua própria cultura e aquilo para que é usado".

É como se tratasse de um processo em que alguém dá sempre qualquer coisa em troca do que recebe, é como um indivíduo se vê no outro - um processo em que as duas partes da equação saem modificadas. A postura transcultural tem a ver (Lopes, 2017) com a capacidade de conectar com pessoas de diferentes línguas e culturas e de pôr essas línguas e culturas em conjunto e reciprocidade para melhorar as vivências de cada um e de todos: a capacidade que assegura que aprendamos a adquirir os conhecimentos e as habilidades necessárias para funcionar na nossa própria cultura - a intraculturalidade - e funcionar na cultura dos outros indivíduos - a interculturalidade que, por vezes, diz respeito à relação entre maiorias culturais e minorias culturais. A intraculturalidade e a interculturalidade são posturas-componente da transculturalidade - que enfatiza a integração através da troca e da interacção, sendo a produção do conhecimento e a sua disseminação contextualizada e participando nela, de forma ampla e participativa, múltiplos e variados actores da sociedade.

\section{GLOBALIZAÇÃo, RELAÇÃo E LUSOFONIA}

Há pouco mais de uma década, discutia (Lopes, 2004, pp. 232-235) a questão dos universais linguísticos e a sua relação com a chamada "desbabelização" da humanidade. 
Retomo o assunto, incluindo a sua contextualização histórica. Em 1951, uma comissão francesa enquadrada pela Unesco, que incluia Gougenheim, começou por elaborar um projecto - uma forma simplificada do Francês para uso internacional - que foi inicialmente chamado de "Francês de Base", posteriormente "Francês Elementar", e por fim "Francês Fundamental". O vocabulário era considerado diminuto, mas a maior crítica ao projecto de linguagens simplificadas era que se achava que ele visava impedir a progressão e desenvolvimento espiritual e intelectual das largas camadas populares, em especial, no continente africano. Assim, amplamente criticados, os objectivos iniciais do "Francês Fundamental" como língua de difusão e potencialmente como língua universal, como se pretendia, acabariam por se circunscrever ao objectivo muito mais modesto de um programa metodológico para o ensino da língua.

Por outro lado, a que ficou mais famosa e que teve mais impacto destas tentativas foi sem dúvida o "Basic English", programa lançado com o ambicioso intuito de resolver o problema do multilinguismo, como diziam os seus mentores. Assim, nem a tentativa francesa de pesquisa nem a inglesa conseguiam concretizar a "desbabelização" da humanidade, quedando-se, pois, por resultados muito mais modestos, do tipo "fornecer métodos de ensino aos professores de língua". Como grandes línguas de comunicação mais ampla, nem o francês, nem o inglês conseguiam resolver à época o desejo de concretização de uma única língua universal, depois de goradas tentativas anteriores de introdução e uso de línguas artificiais como línguas universais.

E em Moçambique o que se passou em relação ao Português fundamental? À altura da Independência Nacional decorria no então Departamento de Letras Modernas da Faculdade de Letras da Universidade Eduardo Mondlane em Maputo um projecto designado de "Português Fundamental" que, entre outros objectivos, aspirava à construção de uma matriz vocabular de 2000 elementos. Em minha opinião, o "Português Fundamental" partilhou muitos dos traços caracterizantes da abordagem metodológica de experiências precursoras, em particular, a francesa. Reagindo contra as ideias behavioristas que orientavam a filosofia e a psicologia americana na década de 50, Noam Chomsky argumentava então que toda e qualquer criança aprendia a falar e a compreender uma língua através de uma determinada capacidade estruturada e inata para esse fim. Para Chomsky, o talento congénito para a fala e compreensão evidencia que a consciência verbal assenta num quadro invisível de universais abstractos que são limitados em número e que são o que faz gerar o número ilimitado de possíveis transformações numa determinada língua; que toda e qualquer língua humana depende de uma gramática generativa transformacional e que a ênfase recai nas propriedades intrínsecas partilhadas por cada língua. Na realidade a linguística geral moderna assenta, em considerável medida, nos princípios da gramática generativa, como foram originariamente definidos por Chomsky há mais de meio século. E graças a esse trabalho de Chomsky sobre a natureza da linguagem, conseguimos hoje compreender melhor alguns aspectos da estrutura da comunicação humana: o seu modelo mental posteriormente adoptado é explicitamente computacional, assumindo a existência de padrões pré-determinados que orientam cada frase que o ser humano fala. 
Mas ao mesmo tempo, a pretendida e incessante busca dos universais linguísticos não se situava ela própria na mesma lógica das tentativas de desbabelização? Será que quanto mais se realça a problemática da universalidade, com menos penumbras ficamos sobre o conhecimento e funcionamento da linguagem? No âmbito da literatura, recordo, por analogia, a passagem de um texto de José Craveirinha (1954), "Consciência de raça", publicado no Semanário Brado Africano, quando se referia ao que considerava ser a ausência de uma cultura literária de expressão africana em Moçambique e o que entendia ser necessário fazer: "não abdicar de uma cultura indígena, nem renegar uma corrente europeia, quando de tal enxerto pode surgir uma beneficiação integral na riqueza do ritmo expressional duma forma literária". E continuou dizendo, "deste princípio surgiu o grito do poeta Senghor, do Senegal: 'Porque não unir as nossas duas claridades a fim de suprimir todas as sombras?'”

Sabemos que os processos de homogeneização parecem gerar sempre outros novos processos de homogeneização no seu seio, como aconteceu com a fragmentação do latim nas línguas românicas. Mas muitas transformações têm lugar silenciosamente, uma vez que o poder nestes tempos novos já não procura confrontar a diversidade; agora, tenta, sim, controlá-la, como diz Mosquera (2001, p. 32):

é óbvio que a globalização não consiste de uma inter-conexão efectiva de todo o planeta por meio de uma grelha articulada de comunicações e de trocas. A globalização é sim um sistema radial que se estende de diversos centros de poder com dimensão variada a múltiplas zonas económicas bastante diversificadas. Tal estrutura implica a existência de vastas zonas de silêncio, praticamente sem ligação entre si ou apenas ligadas indirectamente por via das metrópoles...A globalização melhorou sem dúvida as comunicações a um nível extraordinário, dinamizou e pluralizou a circulação cultural e criou uma consciência mais pluralista. Contudo, fê-lo através dos mesmos canais seguidos pela economia, reproduzindo-se assim, em larga medida, as estruturas do poder.

No recente colóquio (5/10/2017) ocorrido na Universidade Politécnica de Maputo e a propósito da investigação, disseminação do conhecimento e produção cultural, Moisés Martins destacou a relação entre as coisas, línguas, culturas e indivíduos de todos os quadrantes como algo fundamental no mundo competitivo de hoje em que tudo tem valor económico e financeiro, incluindo pessoas, almas e espíritos. Já no seu capítulo de 2014, intitulado "Língua portuguesa, globalização e lusofonia", Martins havia utilizado o termo relação quando realça o ponto de vista de Macedo (2013), desenvolvido na sua tese de doutoramento:

este projecto convoca a questão da diversidade do mundo lusófono, colocando-se a questão com que já se havia confrontado a expansão marítima portuguesa: a de uma descoberta noética, também a de uma filosofia da integração, e ainda a de uma ideologia da dominação, enquanto conexões da relação [ênfase é minha] com o mundo diverso. (Martins, 2014, p. 28) 
Considero importante a palavra e o conteúdo do termo relação e considero relevantes reflexões sobre o termo no contexto da discussão sobre os universais. O meu ponto de vista é que a noção de relação é feita de todas as diferenças à nossa volta e no mundo, e que nenhuma diferença deve ser esquecida por mais pequena que seja ou que possa parecer. Se adoptarmos a relação como abordagem, o que é que fazemos, realmente? 0 que fazemos é gradualmente afastarmo-nos da ideia do universal e, em última instância, da ideia da globalização, incluindo a chamada "globalização cosmopolita" e "globalização multiculturalista", mesmo que esta surja associada ao multiculturalismo (Martins, 2014, p. 24). Para tratar da interconectividade e interdependência, a noção da relação parece-me mais útil que a noção de Globalização ou a dos universais.

O universal na linguística ou em qualquer outra ciência social ou humana é uma abstração e como tal pode orientar-nos apenas para o que é considerado principal fazendo-nos esquecer a pequena diferença. Mas a relação, que é total, não nos deixa fazer isso porque a relação nunca é feita de grandes diferenças. A este propósito, Édouard Glissant, em conversa com o maliano Manthia Diawara, a bordo do paquete The Queen Mary II, navegando de Southampton para Nova lorque, em Agosto de 2009, disserta sobre esta noção central nas suas reflexões sobre a cultura e as travessias no mundo (ou melhor, as passagens, termo mais amplo que inclui os oceanos, não requerendo assim margens à vista):

porque é que eu preciso mesmo de compreender o Outro com a finalidade de viver próximo dele e trabalhar com ele? Eis uma das leis da Relação. $\mathrm{Na}$ Relação, os elementos não se misturam de qualquer maneira, não se perdem de qualquer maneira. Cada elemento pode manter a sua autonomia, a sua qualidade, mesmo quando se acostuma às essenciais qualidades e diferenças dos outros. Cada diáspora é a passagem da unidade para a multiplicidade. A única universalidade hoje é a universalidade das relações que têm por base a diversidade em vez da unidade. A multiplicidade na totalidade é totalmente a diversidade...Não há uma verdade absoluta, mas sim verdades. Tudo está vivo; tudo é uma Relação de diferenças, não de contrários, mas sim de diferenças. Consequentemente, a dialéctica não é uma abordagem linear na direcção daquilo que é contrário. A dialéctica é um rizoma total do que é diferente... (Diawara, citado em Barson \& Gorschlüter, 2010, p. 63)

E tendo achado interessante esta relação entre a dialéctica e o rizoma, no final da citação, ocorreram-me à mente várias imagens do maior cajueiro do mundo, o cajueiro de Pirangi, equivalente a setenta cajueiros de dimensão normal, que tive o privilégio de conhecer, a poucos quilómetros a sul da cidade de Natal no nordeste brasileiro. Em vez de crescer para cima, os galhos do cajueiro cresceram e continuam a crescer para os lados, curvando-se para o solo, devido ao seu peso, ao mesmo tempo que se vão criando novas raízes neste gigante cajueiro que cobre cerca de oito mil metros quadrados e uma circunferência de quinhentos metros. O tipo de caule aéreo (neste caso) 
cresce horizontalmente rente ao solo, um autêntico rizoma, em termos botânicos e cujo conceito foi usado epistemologicamente na teoria filosófica por Deleuze e Guattari (1980/2004) com o sentido de captar multiplicidades, contrariamente ao conceito de conhecimento arborescente, com conexões verticais. Como modelo para a cultura e artes, o rizoma apresenta-se como polo de atrações e influências, sem preocupação com o princípio ou o fim das coisas, situando-se sempre no meio de cadeias e organizações do poder, incluindo as lutas e os desafios sociais, científicos e artísticos.

\section{Lusofonia, Política Linguística e Planificação Linguística}

No estruturado capítulo de Martins (2014, p. 25), é relevante a referência feita à designação sistema ecológico linguístico que, para além da experiência moçambicana, tem por base experiências híbridas e não-híbridas no mundo. Trata-se de experiências eminentemente sociais e linguísticas, inseparáveis do seu meio-ambiente, no qual as línguas e práticas culturais se multiplicam, se cruzam e se influenciam umas às outras, gerando híbridos, na maior parte das situações.

Cerca de duzentos e sessenta milhões de falantes no mundo tornaram e continuam a tornar a língua portuguesa numa língua pluricêntrica e dinâmica, criando-se pressões que actuam em todas as direcções no seio do amplo sistema ecológico linguístico do Português. A língua portuguesa em Moçambique é necessariamente parte (não parte isolada) desse complexo sistema, que se amplifica através de Portugal, Brasil e dos seis estados africanos e asiáticos (Timor-Leste) que têm o Português como língua oficial, que se amplifica através de comunidades e regiões como as de Macau, Goa, Damão e Diu, e faixas ao longo do estreito de Malaca, e ainda através de comunidades constituídas pelas chamadas diásporas (cerca de sete milhões de falantes), de número significativo em países não-lusófonos, como sejam a República da África do Sul, os Estados Unidos da América, a Bélgica e a França, entre outros. Defendo que compreender o sistema ecológico linguístico do Português é indispensável para o que puder ser melhor definido como lusofonia. Do mesmo modo que a ecologia mostra que a sobrevivência biológica é essencialmente possível através de uma variedade de formas, do mesmo modo vejo a sobrevivência linguístico-cultural e civilizacional das diferentes nações e povos na terra.

Num amplo e imaginado espaço em construção, que parte da língua portuguesa e de múltiplos e variados laços históricos como base comum, e numa perspectiva de abordagem translinguística e transcultural do conceito, a lusofonia, que entendo se vai desenvolvendo como uma maneira de ser e de estar, busca o partilhado enriquecimento espiritual, social e económico dos povos e sociedades que dela são parte integrante.

De certa forma, a peculiaridade e a idiossincrasia constantes desta formulação-tentativa foram sendo estabelecidas, em particular, através do ponto de vista sobre a lusofonia em Ndhaneta (Lopes, 2012) e na sequência do comentário que a esse respeito mereceu de Martins (2012, s.p.), a saber:

acho este ponto de vista sobre a lusofonia muito interessante. Começa com a realidade actual das sociedades multiculturais que se nos impõe 
- sociedades de mistura de etnias, do ocidente e do oriente, do norte e do sul. Não esquece a história, uma história de violência, dado que a história da expansão marítima e territorial dos povos ocidentais para oriente impôs a colonização do oriente pelo ocidente. Passa depois ao fundamental: a importância das línguas e das culturas locais, em nome do respeito pela diversidade e pelo outro, no actual processo de mundialização das economias, onde as línguas e as culturas dos antigos povos colonizadores mantêm a hegemonia. A lusofonia, a menos que não passe de um neo-colonialismo simbólico, não pode, pois, ter uma centracção lusa - isso seria (será) o seu maior equívoco.

E reforço esta posição, concordando, com um extracto mais recente do mesmo autor (Martins, 2014, p. 25):

a lusofonia, ao invés da homogeneização empobrecedora e de sentido único, estabelecida pela globalização cosmopolita, tem a virtude do heterogéneo; a sedução de uma rede tecida de fios de várias cores e texturas, uma rede capaz de resistir à redução do diverso a uma unidade artificial.

Realizaram-se já várias conferências de Linguística Aplicada (LA) e outras sobre a internacionalização da língua portuguesa, incluindo o "Plano de Acção de Lisboa", adoptado na "X Conferência da CPLP" de Díli em 2014 para esse efeito. A meu ver, são necessários maiores esforços com vista a articular as importantes dimensões da Política Linguística e da Planificação Linguística no tratamento das inúmeras questões envolvendo a lusofonia, incluindo o facto de que, ao projectar-se como língua internacional, a língua portuguesa tem o potencial de, através de si, poder ajudar a promover, em todos os sentidos, as nações e comunidades que falam a língua portuguesa como língua materna, língua segunda, língua estrangeira e/ou língua na diáspora. Argumentei há algum tempo (Lopes, 2015, pp. 197-200) e continuo a pensar que, para benefício no tratamento de múltiplas questões sociais, culturais e históricas no seio da linguística, a LA poderia ser concebida e operar como uma interface fronteiriça, ocupando-se da terra de ninguém entre a Planificação Linguística, que é a teoria científica e a Política Linguística, que é a teoria indigenizada, ou seja, a teoria da prática.

A Planificação Linguística, outrora conhecida por 'engenharia linguística' (language engineering), contribui através de um conjunto de actividades que visam operar mudanças linguísticas numa determinada comunidade, e cuja intenção, ao nível das autoridades competentes, assenta na preservação da identidade cultural, na manutenção da ordem civil, e no melhoramento da comunicação (Lopes, 1999, pp. 104-125; 2002, pp. 18-22). A Planificação Linguística mantém laços estreitos de relacionamento com o campo da linguística social, que estuda as forças sociais que influenciam a mudança linguística e os tipos de mudança motivados por essas forças, como apropriadamente dizem Kaplan e Baldauf (1997, p. 307) ao defender que a Planificação Linguística é provavelmente a forma suprema da Linguística Aplicada, entendendo-se o tratamento da 
linguagem como fenómeno eminentemente social, tanto no plano do corpus, como no plano do estatuto:

queremos argumentar que a Planificação Linguística constitui a forma suprema da Linguística Aplicada; ...algumas noções da teoria gramatical são centrais para as acções referentes ao corpus. Mas as acções relacionadas com o estatuto requerem uma abordagem bastante diferente para com a definição da linguagem e para com a compreensão da inter-relação entre populações humanas e a(s) língua(s) que usam ao se comunicarem entre uns com os outros.

A Planificação Linguística deve especificar os objectivos que a política visa atingir e enunciar as propostas de política. Embora reconhecendo a importância do espaço para as utopias, qualquer formulação de políticas que não indique a sua operacionalização pode revelar-se inútil. $O$ facto de não poderem ser implementadas pode indicar que tiveram por base uma análise incompleta ou não suficientemente rigorosa da situação que se pretende superar.

O problema a resolver parece ser de como reunir todos os recursos que são precisos especificamente para os diferentes grupos-alvo em presença e como satisfazer as necessidades relacionadas com a língua desses mesmos grupos. Assim, ao basear-se na natureza presente e dinâmica desses grupos-alvo, a política deve descrever os traços de cada grupo que são relevantes para a identificação das necessidades de língua, actuais e futuras, e para a identificação dos passos a dar para a sua satisfação.

Argumenta-se que a elaboração pensada da política de língua assim como a adequada planificação da sua gestão constituem elementos fundamentais visando maximizar a familiaridade e consciencialização dos grupos-alvo em relação ao Português, e visando igualmente maximizar o seu potencial de uso nos domínios oficial, comercial, técnico e cultural no âmbito da lusofonia. Apresento, de seguida, um esboço preliminar de programa de trabalho constituído por três fases com vista a articular a planificação e política linguísticas no domínio da lusofonia e numa perspectiva transdisciplinar com recurso à linguística aplicada.

FASE DA IDENTIFICAÇÃo E DESCRIÇÃO DA NATUREZA HISTÓRICO-LINGUÍSTICO-CULTURAL DOS PAÍSES/SOCIEDADES

O ponto de partida para delinear uma política de língua portuguesa é identificar e descrever, essencialmente, a natureza histórico-linguístico-cultural dos países e sociedades que a política visa servir (Lopes, 2013b, pp. 30-33), com particular enfoque, de entre outros, os seguintes elementos:

\section{A. Diversidade linguística e Cultural}

1. Nível de "elevada diversidade linguística" de cada país, que é importante à partida para melhor enquadrar as estratégias de difusão, estudo e desenvolvimento do Português 
Neste contexto é útil a definição proposta por Robinson (1993, p. 54) para o conceito de "elevada diversidade linguística", designadamente: "uma situação em que não há uma percentagem superior a 50\% da população que fale a mesma língua"; e acrescentando ainda que: "uma classificação segundo o grau de diversidade linguística não deve basear-se no número absoluto de línguas faladas num país, mas sim na percentagem da população que fala uma dada língua".

2. Nível de composição plurilingue e pluricultural dos grupos-alvo

Por exemplo, para Moçambique e Angola, membros da SADC (Comunidade para - Desenvolvimento da África Austral), e Guiné Equatorial membro da CPLP (como Moçambique e Angola) qual é a situação destes países e de outros que têm o Português, o Inglês ou o Francês como línguas europeias oficiais? Conhecer, com propriedade, a geografia plurilingue e pluricultural é importante para o delineamento de estratégias de negociação para uma maior difusão e promoção do Português em contextos plurilingues e pluriculturais.

\section{B. DEPENDÊNCIA E INTEGRAÇÃo ECONÓMICA E EMPRESARIAL}

3. Nível de dependência económica em relação ao comércio interno e externo por parte de cada país/sociedade, assim como o nível da sua integração económica no contexto do resto do mundo

Após a identificação e descrição da natureza histórico-linguístico-cultural dos países/ sociedades, sugerem-se os seguintes passos:

a) enunciar as respectivas necessidades psicológicas, económicas, políticas e culturais ao nível dos países/sociedades e pessoas;

b) formular neste contexto os objectivos e as metas;

c) fazer propostas de política, estabelecendo-se prioridades em relação aos países, sociedades e grupos-alvo a abranger;

d) elaborar recomendações no que diz respeito à implementação da política; e

e) alinhar indicadores de sucesso para a avaliação da política e sua implementação.

É claro que o sucesso de toda a planificação, envolvendo os fazedores de política (policy-makers) e os grupos-alvo, e conectando com as relevantes organizações nacionais, regionais, continentais e inter-continentais, assenta em pressupostos de atitude fundamentais, a saber:

1. que a língua portuguesa é pertença de todos os que a queiram falar e/ou usar;

2. que a língua portuguesa se reveste de múltiplas identidades e tradições e que, por isso, o uso, o desenvolvimento e os estudos desta língua devem ser sempre contextualizados e sem prejuízo para as línguas e culturas com que coabita - fundamental neste âmbito posturas translinguísticas e transculturais. 


\section{FASE DA ENUNCIAÇÃo DAS NECESSIDADES}

\section{A identificação e descrição da natureza histórico-linguístico-cultural dos países/socie- dades conduz-nos à especificação de determinadas necessidades, como sejam as neces- sidades requeridas pelos destinatários da política em termos do desenvolvimento do seguinte:}

1. a proficiência nas quatro habilidades linguístico-comunicativas tradicionais, e também a fluência; a proficiência tem a ver com as habilidades de compreensão da fala e habilidades do processamento da escrita - o exercício da proficiência é sobretudo praticado por meio do acto de ler e escrever, enquanto que a fluência (Lopes, 2017, 2018, p. 40) refere-se essencialmente à prosódia da língua, à pronúncia e ao timing do diálogo;

2. técnicas que auxiliem na comparação e contraste das línguas com que a língua portuguesa convive/conviverá tanto em termos translinguísticos como transculturais (Lopes, 2016, pp. 22-25; Lopes, Mabasso \& Langa, 2016, pp. 17-23). Neste relacionamento do estudo da língua com os diversos tipos de cultura, é determinante a intervenção do professor experiente, do técnico, do erudito e do conhecedor das problemáticas da linguística aplicada, e a intervenção do tradutor-especialista;

3. atitudes que capacitem (e enfaticamente crianças e jovens) de molde a poderem viver harmoniosamente e para se beneficiarem das sociedades plurilingues e pluriculturais com que estão em contacto ou com que virão a estar num mundo mais amplo. Nas escolas, os alunos devem poder desenvolver uma quinta habilidade linguístico-comunicativa (Lopes, 197, p. 74; 2013a, p. 148) que assenta na compreensão e aceitação do Outro e da sua cultura; nos manuais escolares, as diferentes tradições, hábitos, valores, costumes e práticas culturais não podem ser usados apenas como pano de fundo e como recurso ou expediente para a aquisição apenas de habilidades linguísticas e comunicativas;

4. habilidades que ajudem a formular adequadas políticas de formação linguística e didáctica - são necessários técnicos com pendor educativo, sobretudo fazedores de políticas e decisores (policy-makers e decision-makers), linguistas com especialidade em linguística aplicada, intérpretes e tradutores, leitores de língua L1 (língua primeira), L2 (língua segunda) e Le (língua estrangeira). Os fazedores de políticas identificam e servem-se de ciências relevantes (como a Linguística Aplicada, Linguística Social, as Ciências da Comunicação, os Estudos Culturais, a Psicolinguística e outros domínios como a Economia, a Geografia Demográfica e a Ciência Política) para, de forma transdisciplinar, esclarecer sobre a natureza do problema (da situação) que se pretende resolver e deduzir possíveis soluções. Quando a experiência e o conhecimento teórico-prático da situação (problema) por parte do fazedor de políticas não forem adequados, a política e o modo de implementação propostos serão inapropriados. O fazedor de políticas deve levar-nos a questionar o princípio de gestão na tomada de decisões, isto é, questionar a tentação burocrática de se colocar pessoas eminentes, determinados políticos e executivos como fazedores de políticas e decisores, em vez do devido técnico qualificado, do académico relevante, etc.; e

5. utilização de programas de formação bilingue e plurilingue específicos, incluindo o recurso à auto-aprendizagem (usando certos centros para esse fim), à aprendizagem e-learning, ao ensino à distância com base em determinadas plataformas digitais e tele-conferencing. Como já referi (Lopes, 1997a, p. 34), torna-se imperioso assegurar a qualidade de qualquer intervenção, com tempos realistas de preparação e execução, condições de implementação, uso de metodologias adequadas, materiais didácticos apropriados... e muita vontade política. O pior cenário é vermos políticos, administradores ou fazedores de políticas impacientes e inaptos formularem programas de baixa-qualidade e que, para agravar, são postos em prática, muitas vezes, por técnicos sem a competência adequada, produzindo resultados ínfimos, magros em termos das habilidades e recursos requeridos por indivíduos e quadrantes de diferentes sociedades. 


\section{FASE DE ALINHAMENTO DOS INDICADORES DE SUCESSO}

Quanto à expansão do Português, não valerá a pena reconsiderar a sua relativa importância em termos globais? Equacioná-la de forma mais plurilingue e pluricultural, de acordo com os contextos em que opera? Estas questões talvez possam, de forma exploratória, conduzir-nos a perguntas do tipo:

- quantos europeus e americanos falam o Português?;

- quantos africanos e asiáticos falantes de Português se prevê que venham a falar essa língua em 2050, como L2, Le e como L1, de acordo com metas traçadas?;

- quantos africanos e asiáticos nas regiões em que os países falantes de Português se situam têm actualmente algum conhecimento do Português? O número obedece a alguma razoabilidade? E que previsões há até ao ano de 2050?;

- que papel o Português desempenha/desempenhará nas suas vidas? Desfrutam/desfrutarão dos recursos culturais que a língua proporciona, ou simplesmente utilizam/utilizarão o Português essencialmente como língua veicular?;

- que efeitos tem/terá a globalização económica na demanda pelo Português na CPLP?;

- a evolução de blocos regionais, como o da SADC, ocorre/ocorrerá no sentido da promoção e difusão de línguas francas que desafiam a posição do Português em Moçambique ou Angola?;

- como é que o Português contribui/pode contribuir para a modernização económica de um país como Moçambique mais industrializado?;

- a expansão do Português está a provocar/pode vir a provocar a extinção de várias línguas africanas em África ou asiáticas na Ásia?;

- será que, ao longo destes anos, o Português se tem revelado um recurso importante para cada um dos países da CPLP, proporcionando-Ihes vantagens económicas perante outros concorrentes internacionais agressivos?;

- tem-se estudado/ou quando se pensa começar a estudar a literatura em língua africana ou asiática, prevendo-se inclusivamente o recurso à literatura estabelecida de países vizinhos que partilham a língua africana ou asiática em questão?

\section{Conclusão}

Concluo, acentuando a importância da postura transdisciplinar na pesquina e no processo de ensino-aprendizagem. Em termos transdisciplinares, diferentes investigadores, educadores e educandos trabalham conjuntamente, de modo transversal, através e para além das suas problemáticas, com vista à criação de inovações conceptuais, teóricas, metodológicas e de translação que integrem e ultrapassem abordagens específicas relacionadas com uma única disciplina para tratar um determinado problema comum. Criam-se espaços novos de conhecimento, transitando das relações entre as disciplinas, conceitos e metodologias, de modo proactivo e retroactivo, em busca de soluções para problemas existentes e sentidos na sociedade.

Argumentou-se que não há nem haverá real lusofonia sem partilha, sem reciprocidade, sem interpenetração dos falares e das culturas dos falantes e escreventes das várias línguas que milhões de cidadãos da CPLP utilizam nativa e não-nativamente. $\mathrm{A}$ língua portuguesa será poderosa se for sancionada por muitos, se possível por quase todos, se for reconhecida como língua importante, com dinâmica própria para a mudança 
e cheia de vitalidade, e se for reconhecida como uma importante língua mundial, se a identificação com a língua na qual o falante se revê for também sancionada por outros, incluindo aqueles outros que concedem à língua portuguesa um estatuto de co-cidadania nos seus contextos plurilingues e pluriculturais.

No caso de Moçambique (e de outras nações independentes há menos de meio-século) a situação colonial tornou extremamente difícil a coabitação do Português com as línguas indígenas e de outras línguas implantadas, resultando, pois, na hegemonia da língua portuguesa e na desvalorização das línguas que, pelo menos, a deveriam ter acompanhado, em alguma medida, no seu estatuto e desenvolvimento. Neste contexto, defende-se que os programas de língua portuguesa devem, tanto quanto possível, incorporar acções de língua e cultura que assegurem uma consciente protecção das línguas indígenas com que coexiste em contextos plurilingues e pluriculturais. Será certamente o ponto de partida de uma adequada planificação e política linguística em construção para todos os países da CPLP, e uma possível passagem para a lusofonia, em ideal.

Finalmente, o sistema ecológico do Português, que penetra em diferentes estados, regiões e comunidades no mundo, requer planificações e políticas concertadas, incluindo as relações linguístico-culturais internacionais que forem relevantes para contextos específicos na lusofonia. Por exemplo, tendo em conta a relação privilegiada que Moçambique (assim como outros estados da CPLP) mantém com a República Popular da China, e tendo em conta experiências de intercâmbio no período pós-independência, como aconteceu com a formação especializada em língua portuguesa de vários chineses (alguns hoje Embaixadores em várias partes do mundo) em Moçambique nos anos 70 e 80, através da Faculdade de Letras da Universidade Eduardo Mondlane (UEM), os programas de difusão da língua portuguesa na região da SADC poderiam, por exemplo, beneficiar-se de apoios chineses, incluindo por parte do Instituto Confucius, que criado em 2012 na UEM em Maputo para difusão do Chinês, administra desde o início cursos de curta-duração (de quatro meses) e desde 2016 cursos de licenciatura em língua e cultura chinesa frequentados por centenas de alunos. No Tratado da SADC, Comunidade que agrega quinze países da África Austral, indica-se que as duas línguas oficiais da organização são o Inglês e o Português. Mas o que é facto é que desde 1992, o ano da sua fundação, a Comunidade tem dado passos de muito pequena monta em relação ao uso do Português nas comunicações oficiais, orais e escritas. E poderíamos continuar com mais considerações como, por exemplo, o papel do Inglês em Moçambique, sendo este Estado também membro da Commonwealth. Enfim...muitas coisas susceptíveis de reflexão, a ser feita também através das disciplinas da Planificação Linguística e da Política Linguística, pilares de uma Linguística Aplicada, tal como a entendemos no mundo contemporâneo da diversidade linguístico-cultural e da globalização, autêntica travessia rumo à pretendida lusofonia." 


\section{REFERÊNCIAS}

Barson, T. \& Gorschlüter, P. (Eds.) (2010). Afro modern: journeys through the black Atlantic. Londres:Tate Publishing.

Craveirinha, J. (1954, 6 de novembro). Consciência da raça. O Brado Africano.

Deleuze, G. \& Guattari, F. (1980/2004). A thousand plateaus. Vol. 2 de Capitalism and Schizofrenia. Londres: Continuum.

James, C. (1993). What is applied linguistics? International Journal of Applied Linguistics, 3(1), 17-32. DOI: $10.1111 / j .1473-4192.1993$. tbooo41.x

Kaplan, R. B. \& Baldauf, Jr., R. B. (1997). Language planning: from practice to theory. Sidney: Multilingual Matters.

Lopes, A.J. (1997a). Política linguística: princípios e problemas/ Language policy: principles and problems. Maputo: Livraria Universitária.

Lopes, A. J. (1997b). Language policy in Mozambique: a taboo? In R.K. Herbert (Ed.), African linguistics at the crossroads: papers from Kwaluseni (pp. 485-500). Colónia: Rüdiger Köppe Verlag Köln.

Lopes, A. J. (1998). Introdução: universidade e investigação. In A. J. Lopes (Ed.), Universidade e investigação: comunicações de Maputo (pp. i-xii). Maputo: Livraria Universitária.

Lopes, A. J. (1999). The language situation in Mozambique. In R. B. Kaplan \& R. B. Baldauf,Jr. (Eds.), Language planning in Malawi, Mozambique and the Philippines (pp. 86-132). Clevedon: Multilingual Matters.

Lopes, A. J. (2002). O Português como língua segunda em África: problemáticas de planificação e política linguística. In M. H. M. Mateus (Ed.), Uma política de língua para o Português (pp. 15-31). Lisboa: Edições Colibri.

Lopes, A. J. (2004). Língua, línguas: homogeneizar, heterogeneizar? PROLER, 12, 32-34.

Lopes, A. J. (2012, 23 de agosto). A minha concepção a respeito da lusofonia. Ndhaneta [blogue]. Retirado de http://ndhaneta.blogspot.com/2012/08/ideias-minha-concepcao-respeito-da.html

Lopes, A. J. (2013a). Língua portuguesa em Moçambique: timakas, milandos e desafios. Revista Brasileira, 74, $117-134$.

Lopes, A.J. (2013b). Criando a região inteligente: o caso do português na comunidade do desenvolvimento da África Austral (SADC). Platô - Revista do Instituto Internacional da Língua Portuguesa, 4(2), 28-41.

Lopes, A. J. (2015). Política linguística: terra de ninguém, terra de todos: notas a partir de um posto de observação moçambicano. In M. L. Martins (Ed.), Lusofonia e interculturalidade - promessa e travessia (pp. 197-226). Vila Nova de Famalicão: Húmus. Retirado de http://www.lasics.uminho.pt/ojs/index. php/cecs_ebooks/article/view/2202

Lopes, A. J. (2016). Comunicação translinguística e transcultural com enfoque na linguagem idiomática: uma análise contrastiva discursiva entre o Português, Xichangana e Inglês. Todas as Letras, 18(1), 22-36. Retirado de http://editorarevistas.mackenzie.br/index.php/tl/article/view/8870/5631

Lopes, A. J. (2017). Cutucando a onça com vara longa: da transdiscursividade à transculturalidade na lusofonia. Conferência de abertura (keynote address) ao $7^{\circ}$ Seminário Internacional de Linguística/III Congresso Interdisciplinar de Cortesia/II Simpósio de Linguística Textual: Discurso e Interdisciplinaridade. Campus Anália Franco, Unicsul, São Paulo. 
Lopes, A. J. (2018). O aluno universitário moçambicano PL2 e os caminhos da escrita: Um trilho seguro vale mais do que os dois que puseram a quizumba a mancar. Revista Linha d'Água, 31(1), 29-49. DOI: $10.11606 /$ issn.2236-4242.v31i1p29-49

Lopes, A. J., Mabasso, E. \& Langa, P. (2016). Com Todos os efes e erres: para um léxico de usos idiomáticos - Português-Inglês-Xichangana/With all the bells and whistles: towards a lexicon of idiomatic usage Portuguese-English-Shangaan/Kudlaya Nsuna ni Bawa: Ta Kukongoma marito Ya Kufambelana ni Kutirhisa Svivulavulelo-Xiputukezi-Xinghiza-Xichangani. Maputo: Livraria Universitária.

Macedo, L. (2013). Da diversidade do mundo ao mundo diverso da lusofonia: a reinvenção de uma comunidade geocultural na sociedade em rede. Tese de Doutoramento em Ciências da Comunicação, Universidade do Minho, Braga, Portugal. Retirado de http://hdl.handle.net/1822/28851

Martins, M. de L. (2012, 23 de agosto). Comentário ao apontamento de A. J. Lopes, 'A minha concepção a respeito da Lusofonia', publicado em Ndhaneta 'Caderno Cultural' do Diário Notícias.

Martins, M. L. (2014). Língua portuguesa, globalização e lusofonia. In N. Bastos (Ed.), Língua portuguesa e lusofonia (pp. 15-33). São Paulo: Educ, IP-PUC. Retirado de https://repositorium.sdum.uminho.pt/ handle/1822/29178

Mosquera, G. (2001). Notes on globalisation, art and cultural difference. RAIN Artists'Initiatives Network. Rijksakade-mie van beeldende kunsten, Amsterdão.

Ortiz, F. (1940/1963). Contrapunteo Cubano del Tabaco y el Azúcar. Advertencia de sus Contrastes Agrarios, Económicos, Históricos y Sociales, su Etnografia y su Transculturación. Havana: Consejo Nacional de Cultura.

Osgood, C. E. (1949). The similarity paradox in human learning: a resolution. Psychology Review, 56, $132-143$. DOI: $10.1037 /$ hoo 57488

Pratt, M. L. (2005) Transculturação e autoetnografia: Peru 1615/1980. In M. R. Sanches (Ed.), Deslocalizar a Europa (pp. 231-259). Lisboa: Edições Cotovia.

Rajagopalan, K. (2003). Por uma linguística crítica: linguagem, identidade e a questão ética. São Paulo: Parábola.

Robinson, C. D. (1993). Where linguistic minorities are in the majority: language dynamics amidst high linguistic diversity. AILA Review,10, 52-70.

\section{NOTA BIOGRÁFICA}

Armando Jorge Lopes, mestrado (York, RU, 1982), doutorado (Wales, RU, 1986) e pós-doutorado (USC, Califórnia, 1991 \& Cambridge, RU, 1993), é linguista (Linguística Aplicada) e dedica-se há mais de 45 anos ao ensino de línguas - como explicador de Inglês (1967), professor no ensino secundário (1972-1977), docente, investigador e gestor universitário (1977--) e Professor Catedrático (2000--) na Universidade Eduardo Mondlane (UEM), Moçambique. Tem ensinado em programas de doutoramento e pós-doutoramento também em universidades na Europa, América e outros países de África. Foi Director Pedagógico da UEM (1987-1990), Director-Adjunto da Faculdade de Letras para a Investigação (1993-1996), Chefe do Departamento de Linguística e Literatura (2001-04) e Director da Faculdade de Letras e Ciências Sociais (2007-2012). Foi o Vice-Reitor Académico da Universidade Politécnica de Moçambique (2015-2017). Na África 
Austral exerceu o cargo de Editor-Chefe da LASU, Associação de Linguística das Universidades públicas dos 15 países da SADC (1990-1995) e realizou interpretação simultânea e tradução na SADCC e em outras instituições políticas e económicas em Moçambique e outros países (1975-1994). Publicou 12 livros e uma centena de artigos em revistas internacionais e nacionais.

ORCID: https://orcid.org/oooo-0001-9395-8987

Email: ajplopes@zebra.uem.mz

Morada: Universidade Eduardo Mondlane, Campus Universitário Principal, Av. Julius Nyerere, nr. 3453 Maputo, Moçambique

* Submetido: 14.05.2018

$\because$ Aceite: 13.06.2018 